\title{
Screening for subclinical atherosclerosis by noninvasive methods in asymptomatic patients with risk factors
}

This article was published in the following Dove Press journal:

Clinical Interventions in Aging

27 May 2013

Number of times this article has been viewed

\section{Xavier Castellon \\ Vera Bogdanova}

Department of Cardiology, Private Hospital Athis Mons, Paris, France

Correspondence: Xavier Castellon Department of Cardiology, Private Hospital Athis Mons, D'Athis Mons Site Jules Valles, 38 avenue jules valles, 9|200 Athis Mons, Paris, France

Tel +3363220 8872

$\mathrm{Fax}+33$ | 69388487

Email castellondelaplanaxavier@orange.fr
Abstract: Atherosclerosis is a leading cause of cardiovascular death due to the increasing prevalence of the disease and the impact of risk factors such as diabetes, obesity or smoking. Sudden cardiac death is the primary consequence of coronary artery disease in $50 \%$ of men and $64 \%$ of women. Currently the only available strategy to reduce mortality in the at-risk population is primary prevention; the target population must receive screening for atherosclerosis. The value of screening for subclinical atherosclerosis is still relevant, it has become standard clinical practice with the emergence of new noninvasive techniques (radio frequency [RF] measurement of intima-media thickness [RFQIMT] and arterial stiffness [RFQAS], and flow-mediated vasodilatation [FMV]), which have been used by our team since 2007 and are based on detection marker integrators which reflect the deleterious effect of risk factors on arterial remodeling before the onset of clinical events. These techniques allow the study of values according to age and diagnosis of the pathological value, the thickness of the intima media (RFQIMT), the speed of the pulse wave (RFQAS), and the degree of endothelial dysfunction (FMV). This screening is justified in asymptomatic patients with cardiovascular risk factors (hypertension, diabetes, obesity, dyslipidemia, and tobacco smoking). Studies conducted by RF coupled with two-dimensional echo since 2007 have led to a more detailed analysis of the state of the arterial wall. The various examinations allow an assessment of the degree of subclinical atherosclerosis and its impact on arterial remodeling and endothelial function. The use of noninvasive imaging in screening and early detection of subclinical atherosclerosis is reliable and reproducible and allows us to assess the susceptibility of our patients with risk factors and ensures better monitoring of atherosclerosis, thus reducing the occurrence of cardiovascular events in the long term.

Keywords: radio frequency, RF QIMT, RF QAS, FMV, arterial age, velocimetry, MRI

\section{Introduction}

Atherosclerosis is considered a chronic inflammatory disease related to age, having a long, slow asymptomatic phase. Recent data show that it begins to develop early in life and manifests itself clinically in many patients at a relatively advanced stage. The consequences of atherosclerosis, responsible for cardiovascular diseases, are among the leading causes of morbidity and mortality in the world. It should also be noted that coronary heart disease due to atherosclerosis is increasing. Diagnosis and treatment are a priority, partly because sudden death is the primary consequence of coronary artery disease in $50 \%$ of men and $64 \%$ of women. ${ }^{1}$ Early detection of atherosclerosis has become possible due to new noninvasive imaging techniques 
for patients with risk factors, allowing us to detect subclinical atherosclerosis and minimal changes or damage to the vascular walls, which can be potentially corrected by receiving preventive treatment.

At present, the evaluation of arterial status is possible since the advent of new techniques. These are techniques that allow the study of arterial status and its physiological or pathological remodeling (geometric or functional). In addition, these new techniques are very promising for detecting subclinical atheroma and the degree of infiltration of the arterial wall by measuring the intima-media thickness (IMT), ${ }^{2}$ arterial stiffness (AS), ${ }^{3}$ and the echo particle image velocimetry (EPIV) ${ }^{4}$ used in the calculation of the constraint of the carotid wall and of the level of endothelial dysfunction by the flow-mediated vasodilation (FMV) ${ }^{5}$ method. ${ }^{1-3,25,40}$

To complete the screening protocol, ${ }^{6-8}$ in a few years we will have specific biomarkers directly related to the progression of atherosclerosis (the study of metalloproteases or bioprotease obtained from a sample of urine, or of plasma to be systematically associated with previous methods), so as to refine the results by the end of testing and guide our future treatment decisions. At the moment, these specific biomarkers remain in the research stage. Moreover, all biomarkers currently used in the assessment of cardiovascular risk are low-density lipoprotein cholesterol (LDL-C), high-density lipoprotein cholesterol (HDLC), triglycerides (TG), ultra-sensitive C-reactive protein (us-CRP), glycated hemoglobin, creatinine clearance, von Willebrand factor, myeloperoxidases, cytokines, and other markers of platelet reactivity. ${ }^{9}$ Markers of both oxidative stress ${ }^{10}$ and calcium score ${ }^{11}$ (calculated by coronary computed tomography) are useful in the current screening but unfortunately are not specific in the diagnosis of subclinical atherosclerosis.

The use of new noninvasive imaging techniques in the detection of subclinical atherosclerosis could become a screening panel of reliable and reproducible detection for use in daily practice in asymptomatic patients with risk factors, so as to stratify the risk and reclassify it upward to provide targeted support for patients and develop appropriate preventive measures aimed at reducing the occurrence of cardiovascular events, which are the main vascular targets in public health in the 21 st century. Toward that end, the objective of this research is to promote the screening and early detection of subclinical atherosclerosis in asymptomatic patients with cardiovascular risk factors via mass screening or individual screening. ${ }^{12}$

\section{Cardiovascular risk factors}

Cardiovascular risk factors (CVRFs) are modifiable parameters associated with the occurrence of a cardiovascular event that increase the probability of this event: hypertension increases the probability of death by $13 \%,{ }^{13,14}$ tobacco by $9 \%,{ }^{15-18}$ dyslipidemia by $8 \%$ with its atherogenic effect, and by $7 \%$ malnutrition, as well as increasing the incidence of diabetes, obesity, and high body mass index, except where age remains the only nonmodifiable risk factor. ${ }^{19,20}$ Known CVRFs such as hypertension, ${ }^{29}$ smoking, and diabetes were included in multiple models to assess the risk of a cardiovascular event occurring in the general population. This concept of an overall estimate of risk can predict cardiovascular risk, which plays a key role in individualized therapeutic measures. ${ }^{21,22}$

\section{Cardiovascular intermediate markers}

Cardiovascular integrator markers are quantifiable parameters reflecting the deleterious state caused by risk factors and are linked to the occurrence of clinical events. Integrator markers are universal and are the bridge between risk factors and the occurrence of a cardiovascular event, for which they are directly responsible. ${ }^{23,24}$

\section{Atherogenesis}

The origin of atherosclerosis begins in childhood and evolves in bouts of the disease with lesions of an inflammatory character. Through this inflammation, atheromatosis transforms a localized disease into a generalized illness. The main lesion is the atheroma plaque, which is part of the genesis of the first modifications in the arterial wall - that is to say, microcirculatory disturbances all the way to endothelial dysfunction..$^{25-27}$

\section{Genetic factors}

Atherosclerosis is a multifactor disease of which approximately $40 \%$ of cases are attributed to genetic factors and $60 \%$ to environmental factors. Many ongoing projects are underway on the importance of single nucleotide polymorphisms,

Table I QIMT: IMT results according to age, Study of Athis Mons

\begin{tabular}{lll}
\hline Age (years) & IMT $(\mu \mathrm{m})$ & IMT average $(\mu \mathrm{m})$ \\
\hline $20-30$ & $170-310$ & 240 \\
$30-39$ & $320-390$ & 35 \\
$40-49$ & $400-490$ & 450 \\
$50-59$ & $500-590$ & 545 \\
$60-69$ & $600-700$ & 650 \\
\hline
\end{tabular}

Note: Pathological values: IMT $>900$ microns $(0.9 \mathrm{~mm})$.

Abbreviations: IMT, intima-media thickness; QIMT, measurement of IMT. 
Table 2 QAS pulse wave velocity according to age, Study of Athis Mons

\begin{tabular}{lll}
\hline $\begin{array}{l}\text { Age } \\
\text { (years) }\end{array}$ & $\begin{array}{l}\text { PWV average speed } \\
(\mathbf{m} / \mathbf{s})\end{array}$ & $\begin{array}{l}\text { Speed range } \\
(\mathbf{m} / \mathbf{s})\end{array}$ \\
\hline $20-30$ & 4.5 & $2.5-5.7$ \\
$30-39$ & 6.5 & $5.9-7.3$ \\
$40-49$ & 8.0 & $7.5-8.5$ \\
$50-59$ & 9.0 & $8.6-9.4$ \\
$60-69$ & 10.4 & $9.7-11.1$ \\
\hline
\end{tabular}

Notes: PWV values (male/female) were based on age. ${ }^{48}$ The QAS and QIMT are currently used in the early detection of subclinical atherosclerosis and must be systematically associated with the FMV at the humeral artery to assess the degree of endothelial dysfunction.

Abbreviations: FMV, flow-mediated vasodilatation; PWV, pulse wave velocity; QAS, measurement of arterial stiffness; QIMT, measurement of intima-media thickness.

and approximately 150 genetic markers located on 80 genes showing an association with coronary artery disease have been cataloged. Of these, 10 have been proposed to improve the prediction of cardiovascular risk. ${ }^{27,28}$ Through the development of DNA microarrays, it is now possible to detect 500,000 different polymorphisms in a single trial. These techniques are likely to identify genetic variants capable of bringing forward the prediction of cardiovascular risk further than known risk factors alone. ${ }^{29-32}$

\section{Associated factors}

The existence of several theories on atherosclerosis demonstrates a set of associated factors apart from a detailed lipid and total cholesterol profile (TC-LDL-HDL-TG): changes in blood glucose levels, postmenopausal status (elevated CRP, us-CRP), fibrinogen (in men), left ventricular mass, male sex, advanced age, systolic blood pressure, smoking, body mass index, diameter of the waist, low physical activity, family history, and alcohol. ${ }^{33-37}$

\section{Etiology of inflammation \\ Oxidative stress}

Oxidative stress is the principal etiology and the beginning of the alteration of the arterial wall. It can be defined as an imbalance in the body between the biological levels of antioxidants and free radicals, or between the enzymatic systems of oxygen and free radicals. This imbalance causes side effects by decreasing the bioavailability of nitric oxide (NO), arginine, and adenosine triphosphate, a destructive cascade identified at the arterial wall, followed by the initiation of chronic inflammation, leading to a disruption of the protective functions of the endothelium. The dysfunction of protective mechanisms against atherosclerosis leads to vascular dysfunction and the progressive onset from subclinical lesions to clinical pathological manifestations. Causes that promote oxidative stress are hypoxia, respiratory diseases exacerbated by repeated pulmonary infections, smoking, frequent exposure to the sun, alcohol, and air pollution. ${ }^{38-42}$

\section{Role of the renin angiotensin system}

The renin angiotensin system participates in the remodeling of the arterial wall. Stimulation of the angiotensin II AT1 receptor increases cell adhesion, which allows monocytes to infiltrate the endothelium. Here they transform into macrophages, which then accumulate and become foam cells. These cells secrete cytokines and inflammatory markers (interleukins, CRP) follow the assault. ${ }^{33}$ The inflammatory response alters the arterial wall. The first manifestation of this infrastructural disease remodeling is a disruption of elastic blades of the intima media, along with the migration of smooth muscle cells to the subendothelial space, which transforms into fibrocytes or myofibrocytes. ${ }^{43-46}$

\section{Chronic inflammation}

Chronic inflammation is a result of the major consequences of oxidative stress and renin angiotensin system imbalance associated with the deleterious effect of known risk factors that lead to the alteration of the arterial wall. Inflammation plays a key role in all stages of the formation of vascular lesions maintained and exacerbated by risk factors. Chronic inflammation results in changes in the arterial wall, such as geometric vascular remodeling (the increase in IMT) and functional remodeling. The consequence of chronic inflammation is endothelial dysfunction, which sets in and can be defined as an integrated marker of the damage to arterial walls by classic risk factors. ${ }^{47}$

\section{Study techniques of intermediate markers}

Which technique and what method? Since 2007, noninvasive imaging has been used in the diagnosis of subclinical atherosclerosis, as well as the detailed analysis and more precise calculation of the IMT, the velocity of the pulse wave (PWV), and the degree of endothelial dysfunction at the level of the brachial artery by the FMV method. At present, the techniques and methods used are as follows:

- QIMT: This is the measurement of IMT in the carotid artery - the study of geometric remodeling of the artery (Table 1).

- QAS: This is the study of AS in the carotid artery, measuring the speed of the pulse wave and alpha and beta stiffness parameters - the study of the functional remodeling of the artery (Table 2). 
- FMV method: FMV is a complementary method used to assess the degree of endothelial dysfunction in patients with risk factors and their repercussions at the level of the endothelium. The examination is of the brachial artery - the study of the variation of the mean diameter of the artery and postreactive hyperemia relative to the baseline diameter.

\section{Conducting reviews QIMT}

The thickening of the intima media in the development of atherosclerosis shares the same pathophysiological mechanisms in development and progression. The physiological progression of IMT is $1-5$ microns per year. The increased or pathological IMT is a high-risk marker both for independent and predictor cardiovascular events. IMT etiology increase is linked to hypertension, diabetes, smoking, high body mass index, and dyslipidemia. The main objective of this method is the detection of infraclinical atheroma in the earliest phases in patients with risk factors, but it is also useful in monitoring the progression of IMT in patients with poorly controlled risk factors, such as diet and lifestyle factors or with unsupervised drug treatments. When the IMT is pathological, the risk of stroke and myocardial infarction is predictable. The screening and detection of subclinical atherosclerosis will allow us to achieve specialized care and reduce the frequency of occurrence of cardiovascular events. Completion of the review and technical review of the method was made in accordance with the IMT Mannheim protocol (Mannheim consensus initiated in 2004 and again in 2006). ${ }^{48,49}$

\section{QAS}

AS is an independent marker predictive of cardiovascular events. The review aims to make early detection of functional remodeling of the artery in patients with risk factors, through the study of the PWV and the parameters of the $\alpha$ and $\beta$ rigidity. In this technique, we study the PWV. This allows us to detect early patients with high-speed PWV relative to their age bracket, reflecting early atherosclerotic impregnation occurring before the diagnosis of stiffness according to the value published in various pathological studies $(12 \mathrm{~m} / \mathrm{s})$ is confirmed.

PWV measurement is used to evaluate AS in real time. This measure is intended to assess the degree of aging of the arterial system and its influence on the central pressure and pulse (clinical markers). The QAS used in our study is a reliable and reproducible technique that allows us to achieve real-time calculation of the PWV dimension param- eters of stiffness coefficients $(\alpha, \beta)$ at the carotid level. The pathological threshold of different parameters used by this method of study are the PWV - VOP $\leq 12 \mathrm{~m} / \mathrm{s}$ (age limit 70 years) and the size of the coefficient stiffness parameters $(\alpha, \beta): \alpha \geq 11$ and $\beta \geq 20$.

The measurement technique is first carried out on the scouting ultrasound common carotid artery with a $7.5 \mathrm{MHz}$ transducer in two-dimensional (2D) mode. The measuring window is placed with the line $1 \mathrm{~cm}$ from the bulb, with three alternating $15-\mathrm{mm}$ measurements taken on each common carotid. Color indicators should be parallel to the artery walls, remaining synchronous to the kinetics of said walls. The curve of the PWV must be smooth and morphologically regular and analyzed for 10-12 seconds. The process stops at the moment the standard deviation (SD) is $<5$. The resulting figure distension, called a "spontaneous shutdown procedure," is used to calculate the coefficients of the dimensions of the stiffness parameters.

\section{FMV}

FMV is an additional technical noninvasive, reproducible, inexpensive method used in the indirect assessment of the degree of endothelial dysfunction, directed at the brachial artery and applicable to patients with risk factors. The analysis of the pathological results is correlated with the progression of infra-clinical atherosclerosis. This growth will be compounded by the degree of oxidative stress and severity of risk factors or poor control of the disease. ${ }^{5,50-52}$

\section{Methods}

The measurement technique is based on initial ultrasound detection (with a 7.5 MHz linear transducer in 2D mode) of the humeral artery above the arm's antecubital fossa, followed by radio frequency measurement of the mean diameter and spectral analysis of the baseline blood flow (in $\mathrm{cm} / \mathrm{second}$ ). Once these baseline measurements have been made, an inflatable cuff (with a defined length of $10 \mathrm{~cm}$ ) is placed around the proximal third of the arm and a $300 \mathrm{mmHg}$ occlusive pressure is applied for 5 minutes. The first step is to then measure the baseline brachial artery diameter and flow. The next step is to measure the brachial artery diameter and flow after reactive hyperemia. In case of pathology, a physiological 15-minute arterial recovery period is required before continuing to the second part of the procedure (only in patients presenting endothelial dysfunction diagnosed by radio frequency (FMV)).

The second part of the procedure is the reversibility test, which is used to assess endothelial function (FMV). While NO 
donors were used, we tested the reversibility of the endothelial dysfunction, as well as the additional effect of cyclic monophosphate on the healthy endothelium. The reversibility test with an FMV-NO donor is expressed as the percentage recovery of the arterial diameter after reactive hyperemia compared to the same artery's baseline diameter. ${ }^{45,47,50,51-54}$ In addition to these new technical noninvasive tests for the detection of subclinical atherosclerosis, two new tests have recently emerged, with very encouraging results: echo particle image velocimetry (EPIV) and magnetic resonance imaging (MRI) velocimetry. ${ }^{53-55}$

\section{EPIV}

EPIV is a new technique in the detection of subclinical atherosclerosis, used in measurements of shear wall stress through vector analysis of blood flow velocities of the wall at the carotid bifurcation. It has a technical high-temporal resolution of $0.7 \mathrm{~ms}$ and a spatial resolution of $0.4 \mathrm{~mm}$, combining EPIV contrast with a conventional $2 \mathrm{D}$ echo method. This technique is a synthesis of two technologies: particle image velocimetry and brightness mode ultrasound contrast. The most recent development of micro-bubbles improved imaging based on ultrasonic velocimetry of vascular flow. The parameters analyzed are the vascular speed profile, velocity vector, speed, maps, and hemodynamic blood flow to the wall shear stress (calculating the average shear stress in the arterial wall in dyne $/ \mathrm{cm}^{2}$ ). The contrast agent used is a product of contrast micro-bubbles, which allows a better study of velocities and stresses. The standards used for the wall stress are $-20+5 \mathrm{dyne} / \mathrm{cm}^{2}$ and wall pathological stress $>200 \mathrm{dyne} / \mathrm{cm}^{2} .{ }^{56-59}$

\section{MRI velocimetry}

MRI velocimetry is a very promising technique for the detection of subclinical atherosclerosis. This technique studies the velocity profile, shear rate, and general flow stress of the wall. It is a noninvasive technique, more sensitive and reliable than the EPIV (with the border error between the two techniques of $10 \%$ for MRI). The problem now is that it is not routinely used, and it is not always available on a daily basis. MRI velocimetry has both advantages and disadvantages, due to its high temporal resolution; it is now considered a promising approach for the noninvasive assessment of changes in carotid wall thickness, a marker for subclinical atherosclerosis in young patients with high risk and abdominal adiposity. ${ }^{60-63}$

\section{Biomarkers}

A biomarker is a characteristic objectively measured with sufficient accuracy and reproducibility and evaluated as an indicator of pathological or physiological processes, or as the effect of a drug. At present, most of these biomarkers are used in research, with multiple studies in progress to identify the precise profiles of subjects who could benefit from dosages of these biomarkers. However, some biomarkers we studied open up interesting prospects and play an important role in the study and progression of atherosclerosis.

The presence of high levels of these biomarkers greatly increases the risk of developing cardiovascular disease in healthy subjects with risk factors, or in patients at high risk. If these results are confirmed, it would be possible in the future to identify people at risk for cardiovascular disease and its complications and offer them appropriate treatment. Currently, these biomarkers are still in the research stage with multiple ongoing studies to identify the precise profile of subjects who may benefit from dosage by these biomarkers. The use of biomarkers should be used in asymptomatic patients with risk factors, associated with previously described techniques, for better stratification of risk and the reclassification of patients from intermediate to a higher cardiovascular risk. ${ }^{64}$

In the future, annual control specific biomarkers in patients with risk factors who had a management target will be systematic. ${ }^{65-69}$ An improvement or normalization of biomarkers translates to a significant decrease in the progression of atherosclerosis. This protocol assessment of the arterial age will be associated with protocols Framingham and European System for Cardiac Operative Risk Evaluation (EuroSCORE) and to assess the real risk in patients with cardiovascular risk factors. ${ }^{70-73}$

In the future, monitoring of specific biomarkers once a year should be undertaken in patients with increased values of parameters measured with noninvasive techniques. After standardization, the use of these new techniques will support targeted and good control of risk factors, reflected by a decrease in the progression of atherosclerosis and cardiovascular diseases.

\section{Conclusion}

Traditional risk factors predict future cardiovascular events and are major determinants in the assessment of cardiovascular risk (Framingham score ${ }^{74,75}$ and EuroSCORE ${ }^{76-79}$ ) and the choice of primary prevention strategy. Despite the undeniable progress made in the diagnosis of cardiovascular disease, and especially its management along with a decrease in mortality, cardiovascular disease remains a major cause of morbidity and mortality in Western countries, partly because sudden death is the first evidence of coronary artery disease in $50 \%$ of men and $64 \%$ of women. In future years, it is feared that there will 
be a further increase in the prevalence of cardiovascular disease secondary to the aging population and the rise in obesity and diabetes. Currently the only available strategy to reduce mortality in this population is primary prevention - atherosclerosis screening of the target population. This approach in primary prevention is more effective when it is directed toward the early detection of subclinical atherosclerosis using new noninvasive imaging techniques that add value, not only in the screening of asymptomatic patients with risk factors, but also in the stratification of cardiovascular risk and greater upward reclassification for patients at intermediate risk so that they can receive preventive treatment with targeted support tailored to each patient, thus enabling them to avoid the occurrence of a cardiovascular event in the short and medium term. These new techniques (QIMT, QAS, and FMV) allow us to have an overall picture of the state of physiological or pathological arterial remodeling and the degree of endothelial dysfunction. The results obtained with these techniques in the future will be associated with specific biomarkers to refine the diagnosis of subclinical atherosclerosis. ${ }^{80-84}$

These abnormal or pathological results significantly increase the amount of predictive information provided by traditional risk factors. The descriptions above show that the three noninvasive imaging tests (QIMT, QAS, and FMV) are promising technologies. These techniques are reliable, reproducible, and inexpensive, and we believe in the near future that doctors will have new intermediate markers to evaluate early subclinical changes in the arterial wall and will introduce them into their clinical assessments and in the monitoring of patients. ${ }^{85-95}$

\section{Disclosure}

The authors report no conflicts of interest in this work.

\section{References}

1. Mihailidou AS, Ritchie R, Ashton AW (2013). Sex Differences in Sudden Cardiac Death. In: Gaze D, editor. Ischemic Heart Disease. Available from: http://www.intechopen.com/books/ischemic-heart-disease/sexdifferences-in-sudden-cardiac-death.

2. Castellon X, Bogdanova V. QIMT by radio frequency (examination of tracking). Method of evaluation thickness of the intimae media among patients having cardio vascular risk factors. Proceedings of Euro Prevent Conference; 2010 May 5-7; Prague, Czech Republic.

3. Castellon X, Bogdanova V. Study of arterial rigidity QAS. Arch Cardiovasc Dis. 2011;3(1):85-86.

4. Sengupta PP, Pedrizzetti G, Kilner PJ, et al. Emerging trends in CV flow visualization. JACC Cardiovasc Imaging. 2012;5(3):305-316.

5. Castellon X, Bogdanova V. Analysis of endothelial function by radiofrequency coupled with two-dimensional echocardiography: the value of flow-mediated vasodilatation. A study of 25 cases. Proceedings of the 4th Conference of SENS, 2009 Sep 3-7 Cambridge, UK.

6. Castellon X, Bogdanova V. Screening protocol of subclinical atherosclerosis with noninvasive imaging methods, by radio frequency (RF) echo 2D. Arch Cardiovasc Dis. 2012;4(1):49.
7. Castellon X, Bogdanova V. Screening protocol of sub clinical atherosclerosis by radio frequency (RF) coupled with $2 d$ echo. Proceedings of the Conference of Evolving Challenges in Promoting Cardiovascular Health; 2011 Nov 4-5; Barcelona, Spain.

8. Castellon X, Bogdanova V. Protocol of screening of sub clinical atherosclerosis by radio frequency (RF) coupled with 2D echo. Proceedings of the 5th: Conference of SENS, 2011 Aug 31-Sep 4; Cambridge, UK.

9. Revkin JH, Shear CL, Pouleur HG, Ryder SW, Orloff DG. Biomarkers in the prevention and treatment of atherosclerosis: need, validation, and future. Pharmacol Rev. 2007;59(1):40-53.

10. Charniot JC, Cosson C, Castellon X, et al. Comparison of oxidative stress status in patients with cardiogenic shock due to severe left ventricular dysfunction. Rejuv Res. 2009;12(s1):S17-S59.

11. Shaw LJ, Raggi P, Callister TQ, Berman DS. Prognostic value of coronary artery calcium screening. in asymptomatic smokers and non-smokers. Eur Heart J. 2006;27:968-975.

12. Bampi AB, Rochitte CE, Favarato D, Lemos PA, da Luz PL. Comparison of non-invasive methods for the detection of coronary atherosclerosis. Clinics (Sao Paulo). 2009;64(7):675-682.

13. Alexander RW. Theodore Cooper Memorial Lecture. Hypertension and the pathogenesis of atherosclerosis. Oxidative stress and the mediation of arterial inflammatory response: a new perspective. Hypertension. 1995;25:155-161.

14. Berenson GS, McMahan CA, Voors AW. Cardiovascular Risk Factors In Children: The Early Natural History Of Atherosclerosis And Essential Hypertension. New York, NY: Oxford University Press; 1980.

15. Duenas MR. Tobacco smoke and atherosclerosis progression. JAMA. 1998;280(1):32-33.

16. Haapanen A, Koskenvuo M, Kesäniemi YA, Heikkilä K. Carotid arteriosclerosis in identical twins discordant for cigarette smoking. Circulation. 1989;80:10-16.

17. Richard JL, Ducimetiere P, Cambien F. Tobacco, mortality and morbidity of atherosclerotic cardiovascular diseases - a prospective study in Paris. Bull Schweiz Akad Med Wiss. 1979;35(1-3):51-69. French.

18. Howard G, Wagenknecht LE, Burke GL. Cigarette smoking and progression of atherosclerosis: The Atherosclerosis Risk in Communities (ARIC) Study. JAMA. 1998;279(2):119-124.

19. Wissler RW, Strong JP. Risk factors and progression of atherosclerosis in youth. PDAY Research Group. Pathological Determinants of Atherosclerosis in Youth. Am J Pathol. 1998;153(4): 1023-1033.

20. Berenson GS, Srinivasan SR, Bao W, Newman WP 3rd, Tracy RE, Wattigney WA. Association between multiple cardiovascular risk factors and atherosclerosis in children and young adults. The Bogalusa Heart Study. N Engl J Med. 1998;338:1650-1656.

21. Kataoka Y, Shao M, Wolski K, at al. Multiple risk factor intervention and progression of coronary atherosclerosis in patients with type 2 diabetes mellitus. Eur J Prev Cardiol. Epub January 31, 2012.

22. Nicholls SJ, Tuzcu EM, Crowe T. Relationship between cardiovascular risk factors and atherosclerotic disease burden measured by intravascular ultrasound. J Am Coll Cardiol. 2006;16;47(10):1967-1975.

23. Grimbone MA Jr. Vascular endothelium : an integrator of pathophysiologic stimuli in atherosclerosis. Am J Cardiol. 1995;75(6 Suppl 1): 67B-70B.

24. Wang SS, Schadt EE, Wang H, et al. Identification of pathways for atherosclerosis in mice: integration of quantitative trait locus analysis and global gene expression data. Circ Res. 2007;101:e11-e30.

25. Blankenberg S, Barbaux S, Tiret L. Adhesion molecules and atherosclerosis. Atherosclerosis. 2003;170(2):191-203.

26. Reiner Z, Tedeschi-Reiner E. New information on the pathophysiology of atherosclerosis. Lijec Vjesn. 2001;123(1-2):26-31. Croatian.

27. Cyrus T, Witztum JL, Rader DJ, et al. Disruption of the 12/15-lipoxygenase gene diminishes atherosclerosis in apo E-deficient mice. J Clin Invest. 1999;103(11):1597-1604.

28. Falk E. Pathogenesis of atherosclerosis. J Am Coll Cardiol. 2006; 47(8s1):C7-C12. 
29. Atherosclerosis: basic mechanisms. Oxidation, inflammation, and genetics. Circulation. 1995;91(9):2488-2496.

30. Lusis AJ, Mar R, Pajukanta P. Genetics of atherosclerosis. Annu Rev Genomics Hum Genet. 2004;5:189-218.

31. Cohen JC, Zannis VI. Genes affecting atherosclerosis. Curr Opin Lipidol. 2001;12(2):93-95.

32. Puddu P, Cravero E, Puddu M, Muscari A. Genes and atherosclerosis: at the origin of the predisposition. Int $J$ Clin Pract. 2005;59(4):462-472.

33. Conlan FM, Folsom AR, Finch A, et al. Associations of factor VIII and von Willebrand factor with age, race, sex, and risk factors for atherosclerosis. The Atherosclerosis Risk in Communities (ARIC) Study. Thromb Haemost. 1993;70(3):380-385.

34. Ridker PM, Stampfer MJ, Rifai N. Novel risk factors for systemic atherosclerosis: a comparison of C-reactive protein, fibrinogen, homocysteine, lipoprotein(a), and standard cholesterol screening as predictors of peripheral arterial disease. JAMA. 2001;285(19):2481-2485.

35. Kullo IJ, Gau FT, Tajik AJ. Novel risk factors for atherosclerosis. Mayo Clin Proc. 2000;75(4):369-380.

36. Lagrand WK, Visser CA, Hermens WT, et al. C-reactive protein as a cardiovascular risk factor: more than an epiphenomenon? Circulation. 1999;100:96-102.

37. Marmot MG, Rose G, Shipley MJ, Thomas BJ. Alcohol and mortality: a U-shaped curve. Lancet. 1981;1(8220 Pt 1):580-583.

38. Beaudeux JL, Delattre J, Therond P, Bonnefont-Rousselot D, LegrandA, Peynet J. Le stress oxydant, composante physiopathologique de l'athérosclérose [Oxidative stress in the atherosclerotic process.] Immuno-analyse \& Biologie Spécialisée. 2006;21(3):144-150.

39. Singh U, Jialal I. Oxidative stress and atherosclerosis. Pathophysiology. 2006;13(3):129-142.

40. Harrison D, Griendling KK, Landmesser U, Hornig B, Drexler H. Role of oxidative stress in atherosclerosis. Am J Cardiol. 2003;91(3A): $7 \mathrm{~A}-11 \mathrm{~A}$

41. Bonomini F, Tengattini S, Fabiano A, Bianchi R, Rezzani R. Atherosclerosis and oxidative stress. Histol Histopathol. 2008;23(3): 381-390.

42. Stocker R, Keaney JF Jr. Role of oxidative modifications in atherosclerosis. Physiol Rev. 2004;84(4):1381-1478.

43. Ruiz-Ortega M, Lorenzo O, Rupérez M, et al. Fourth International Seminar on Cardiovascular Biology and Medicine: Part II. Role of the renin-angiotensin system in vascular diseases. expanding the field. Hypertension. 2001;38:1382-1387.

44. Duprez DA. Role of the rennin-angiogenesis-aldosterone system in vascular remodelling and inflammation: a clinical review. J Hypertens. 2006;24(6):983-991.

45. Schiffrin EL, Touyz RM. From bedside to bench to bedside: role of renin-angiotensin-aldosterone system in remodeling of resistance arteries in hypertension. Am J Physiol Heart Circ Physiol. 2004;287(2):H435-H446.

46. Touyz RM. Intracellular mechanisms involved in vascular remodelling of resistance arteries in hypertension: role of angiotensin II. Exp Physiol. 2005;90(4):449-455.

47. Intengan HD, Schiffrin EL. Vascular remodeling in hypertension: roles of apoptosis, inflammation, and fibrosis. Hypertension. 2001;38:581-587.

48. Castellon X, Bogdanova V. QIMT by radio frequency (examination of tracking) method of evaluation thickness of the intima media among patients having cardio vascular risk factors. Proceedings of the International Conference on Early Disease Detection and Prevention; 2010 Feb 25-28; Munich, Germany.

49. Castellon X, Bogdanova V. QIMT by radio frequency (examination of tracking), method of evaluation thickness of the intima media among patients having cardio vascular risk factors. Clinical implication: about 150 cases. Proceedings of the 4th International Conference on Oxidative/Nitrosative Stress and Disease; 2009 Oct 28-30; New York, NY, USA.

50. Castellon X. Methods of assessing endothelial function, vasodilation of interest by the intermediate flow. Cardiology Practice. 2006;8,10-12.
51. Charniot JC, Cosson C, Chemouni F, et al. Oxidative stress implications in cardiogenic shock with ischemic or idiopathic severe left ventricular dysfunction: role of etiologies of cardiomyopathies. Archives of Cardiovascular Diseases Supplements. 2010;2(1):29.

52. Charniot JC, Albertini JP, Cosson C, et al. Mid-term follow up of consecutive patients with cardiogenic shock without acute coronary syndrome. Archives of Cardiovascular Diseases Supplements. 2010;2(1):33.

53. Charniot JC, Vignat N, Albertini JP, et al. Oxidative stress in patients with acute heart failure. Rejuvenation Res. 2008; 11(2):393-398.

54. Calermajer DS, Sorensen KE, Gooch VM, et al. Non-invasive detection of endothelial dysfunction in children and adults at risk of atherosclerosis. Lancet. 1992;340(8828):1111-1115.

55. Widlansky ME, Gokce N, Keaney JF, Vita JA. Les implications cliniques de la dysfonction endothéliale [The clinical implications of endothelial dysfunction]. J Am Coll Cardiol. 2003;42(7):1149-1160.

56. Toth PP. Subclinical atherosclerosis: what it is, what it means and what we can do about it. Int J Clin Pract. 2008;62(8):1246-1254.

57. Shaaban AM, Duerinckx AJ. Wall shear stress and early atherosclerosis. a review. AJR Am J Roentgenol. 2000;174(6):1657-1665.

58. Schwartz CJ, Valente AJ, Sprague EA, Kelley JL, Cayatte AJ, Mowery J. Atherosclerosis. Potential targets for stabilization and regression. Circulation 1992;86(6 Suppl):III117-123.

59. Cunningham KS, Gotlieb AI. The role of shear stress in the pathogenesis of atherosclerosis. Lab Invest. 2005;85(1):9-23.

60. Robertson MB, Köhler U, Hoskins PR, Marshall I. Quantitative analysis of PC MRI velocity maps: pulsatile flow in cylindrical vessel. Magn Reson Imaging. 2001;19(5):685-695.

61. Kim T, Seo JH, Bang SS, Choi HW, Chang Y, Lee J. Optimisation de la vélocimétrie MR flux de contraste de phase basée sur des mesures et des contraintes de cisaillement [Optimization of MR phase-contrast-based flow velocimetry and shear stress measurements]. Int $J$ Cardiovasc Imaging. 2010;26 Supp1 1:133-142. French.

62. Vanauker MD, Tacy TA, del Nido PJ, Cape EG. Development of a noninvasive marker of wall shear stress effects in discrete subaortic stenosis. Cardiovascular Engineering. 2001;1(3):137-146.

63. Tsou JK, Liu J, Insana MF. Modeling and phantom studies of ultrasonic wall shear rate measurements using coded pulse excitation. IEEE Trans Ultrason Ferroelectr Freq Control. 2006;53(4):724-734.

64. Charniot JC, Cosson X, Castellon V. Comparison of oxidative stress status in patients with cardiogenic shock due to severe left ventricular dysfunction. Proceedings of the 4th Conference of SENS, 2009 Sep 3-7; Cambridge, UK.

65. Charniot JC, Vignat N, Bonnefont-Rousselot D, et al. Oxidative stress implication in acute heart failure. Proceedings of the 3rd Conference of SENS, 2007 Sep 3-7; Cambridge, UK.

66. Castellon X, Bogdanova V, Charniot JC. QIMT by radio frequency (examination of tracking). Method of evaluation thickness of the intima media among patients having cardio vascular risk factors. Proceedings of the 4th Conference of SENS, 2009 Sep 3-7; Cambridge, UK.

67. Zheng HR, Wang J. A new velocimetry algorithm for optimizing ultrasonic PIV imaging method. Proceedings of the International Special Topic Conference on Information Technology and Applications in Biomedicine; 2008 May 30-31; Shenzhen, China.

68. Li JJ, Fang CH. C-reactive protein is not only an inflammatory marker but also a direct cause of cardiovascular diseases. Med Hypotheses. 2004;62:499-506.

69. Mannucci PM. von Willebrand factor: a marker of endothelial damage? Arterioscler Thromb Vasc Biol. 1998;18:1359-1362.

70. Tsao CW, Preis SR, Peloso GM, et al. Relations of long-term and contemporary lipid levels and lipid genetic risk scores with coronary artery calcium in the framingham heart study. J Am Coll Cardiol. 2012; 60(23):2364-2371.

71. Samelson EJ, Booth SL, Fox CS, et al. Calcium intake is not associated with increased coronary artery calcification: the Framingham Study. Am J Clin Nutr. 2012;96(6):1274-1280. 
72. Towfighi A, Markovic D, Ovbiagele B. Utility of Framingham Coronary Heart Disease Risk Score for predicting cardiac risk after stroke. Stroke. 2012;43(11):2942-2947.

73. Sung KC, Kang SM, Cho EJ, Park JB, Wild SH, Byrne CD. Ferritin is independently associated with the presence of coronary artery calcium in 12,033 men. Arterioscler Thromb Vasc Biol. 2012;32(10):2525-2530.

74. Brindle P, Emberson J, Lampe F, et al. Predictive accuracy of the Framingham coronary risk score in British men: prospective cohort study. BMJ. 2003;327:1267.

75. Rutter MK, Meigs JB, Sullivan LM, D’Agostino RB Sr, Wilson PW. C-reactive protein, the metabolic syndrome, and prediction of cardiovascular events in the Framingham Offspring Study. Circulation. 2004;110:380-385.

76. Lakoski SG, Greenland P, Wong ND, et al. Coronary artery calcium scores and risk for cardiovascular events in women classified as "low risk" based on Framingham risk score: the multi-ethnic study of atherosclerosis (MESA). Arch Intern Med. 2007;167(22):2437-2442.

77. Abbott RD, Wilson PW, Kannel WB, Castelli WP. High density lipoprotein cholesterol, total cholesterol screening, and myocardial infarction. The Framingham Study. Arteriosclerosis. 1988;8(3):207-211.

78. Lange RA. Can you predict what happens when EuroSCORE weds biomarker? J Am Coll Cardiol. 2013;61(6):682-684.

79. Franklin SS, Gustin W 4th, Wong ND. Hemodynamic patterns of age-related changes in blood pressure. The Framingham Heart Study. Circulation. 1997;96(1):308-315.

80. Touboul PJ, Hennerici MG, Meairs S, et al. Mannheim carotid intimamedia thickness consensus (2004-2006). An update on behalf of the Advisory Board of the 3rd and 4th Watching the Risk Symposium, 13th and 15th European Stroke Conferences, Mannheim, Germany, 2004, and Brussels, Belgium, 2006. Cerebrovasc Dis. 2007;23:75-80.

81. Huck CJ, Bronas UG, Williamson EB, Draheim CC, Duprez DA, Dengel DR. Noninvasive measurements of arterial stiffness: repeatability and interrelationships with endothelial function and arterial morphology measures. Vasc Health Risk Manag. 2007;3(3):343-349.

82. Adji A, O'Rourke MF, Namasivayam M. Arterial stiffness, its assessment, prognostic value, and implications for treatment. Am J Hypertens. 2011;24(1):5-17.
83. Laurent S, Cockcroft J, Van Bortel L, et al. European Network for Noninvasive Investigation of Large Arteries. Expert consensus document on arterial stiffness: methodological issues and clinical applications. Eur Heart J. 2006;27:2588-2605.

84. Boutouyrie P, Tropeano AI, Asmar R, et al. Aortic stiffness is an independent predictor of primary coronary events in hypertensive patients. Hypertension. 2002;39:10-15.

85. Meaume S, Benetos A, Henry OF, Rudnichi A, Safar ME. Aortic pulse wave velocity predicts cardiovascular mortality in subjects $>70$ years of age. Arterioscler Thromb Vasc Biol. 2001;21:2046-2050.

86. Bouhanick B, Chamontin B. Should pulse pressure and day/night variations in blood pressure be seen as independent risk factors requiring correction or simply as markers to be taken into account when evaluating overall vascular risk? Diabetes Metab. 2007;33(5):321-330.

87. Lane HA, Smith JC, Davies JS. Noninvasive assessment of preclinical atherosclerosis. Vasc Health Risk Manag. 2006;2(1):19.30

88. O’Rourke MF, Gallagher DE. Pulse wave analysis. J Hypertens Suppl. 1996;14:S147-S157.

89. Gutierrez MA, Higa M, Pilon PE, Rebelo MDS, Lage SG. Quantitative Assessment of Peripheral Arteries in Ultrasound Images. Medical Imaging in Clinical Practice; 2013. Available from: http:// www.intechopen.com/books/medical-imaging-in-clinical-practice/ quantitative-assessment-of-peripheral-arteries-in-ultrasound-images.

90. Libby P, Ridker PM, Maseri A. Clinical cardiology: new frontiers. Inflammation and atherosclerosis. Circulation. 2002;105:1135-1143.

91. Nillson PM, Boutouyrie P, Laurent S. Vascular aging: a tale of EVA and ADAM in cardiovascular risk assessment and prevention. Hypertension. 2009;54:3-10.

92. Cockcroft JR, Wilkinson IB. Arterial stiffness and pulse contour analysis: an age old concept revisited. Clinical Science. 1979;103(4):379-380.

93. Laurent S, Kingwell B, Bank A, Weber M, Struijker-Boudier H. Clinical applications of arterial stiffness: therapeutics and pharmacology. Am J Hypertens. 2002;15(5):453-458.

94. Mackenzie I, Wilkinson I, Cockcroft J. Assessment of arterial stiffness in clinical practice. QJM, 2002;95(2):67-74

95. Simon A, Gariepy J, Levenson J. Ultrasonographic study of the arterial walls: application to the detection of preclinical atherosclerosis. Arch Mal Coeur Vaisseaux. 1997;90(2):7-10. French.
Clinical Interventions in Aging

\section{Publish your work in this journal}

Clinical Interventions in Aging is an international, peer-reviewed journal focusing on evidence-based reports on the value or lack thereof of treatments intended to prevent or delay the onset of maladaptive correlates of aging in human beings. This journal is indexed on PubMed Central, MedLine, the American Chemical Society's 'Chemical Abstracts

\section{Dovepress}

Service' (CAS), Scopus and the Elsevier Bibliographic databases. The manuscript management system is completely online and includes a very quick and fair peer-review system, which is all easy to use. Visit http://www.dovepress.com/testimonials.php to read real quotes from published authors. 